\title{
\&.] ОБШЕСТВЕННАЯ
}

Попов Е.А.

\section{СОЦИАЛЬНАЯ БЕЗОПАСНОСТЬ КАК ЦЕННОСТНО-НОРМАТИВНЫЙ КОМПЛЕКС}

\begin{abstract}
Аннотация: Внимание к проблемам безопасности, эффективным и действенным способам ее обеспечения всё более занимает современную науку не только естественной, но и соииогуманитарной направленности. $B$ различных исследованиях акиенты в основном ставятся на институциональном подходе, обращенном к анализу роли различных государственных и сочиальных институтов в достижении безопасности. Однако важным моментом является и выяснение ценностно-нормативных оснований обеспечения безопасности. Кроме того, в статье особое внимание уделяется изучению явления социальной безопасности в антросоциетальном и культурочентричном аспектах. Культурочентричный подход (и прежде всего аксиологический) позволяет взглянуть на проблему сочиальной безопасности в другом ключе, показать роль культуры и ценностнонормативных установок в обеспечении соџиальной безопасности Социальная безопасность понимается как такое состояние взаимодействия общества, человека, государства и культуры, при котором достигается позитивное состояние всех субъектов и объектов сочиальной реальности. Такой взгляд на социальную безопасность позволяет значительно расширить социокультурный "горизонт" в исследовании обозначенной проблемы и создать более эффективные способы по обеспечению безопасности в обществе.

Review: Security issues and efficient safety enforcement are in the focus of attention of modern science, both natural science and socio-humanitarian disciplines. Most researches emphasize mostly the institutional approach that analyzes the role of different state and social institutions in achieving social security. However, values and standards lying in the basis of security enforcement are an important moment to discover as well. In addition, in his research E. Popov pays special attention to studying the phenomenon of social security in antrosocietal and culturecentered aspects. The culture-centered approach (including axiological approach in the first place) allows to view the security issue in a different light and to show to role of culture and values and moral standards in security enforcement. Social security is understood as a certain state of interaction between society, human, state institution and culture that allows to achieve the positive state of all actors and objects of social reality. Such approach to social security allows to considerably expand the socio-cultural 'horizon' of above mentioned researches and create more efficient methods of security enforcement in the society.
\end{abstract}

Ключевые слова: Безопасность, сочиальная безопасность, общество, обеспечение безопасности, культура, национальная безопасность, опасность, иенности, нормы, государство.

Keywords: Security, social (public) security, society, security enforcement, culture, national security, danger, values, standards, state institution.

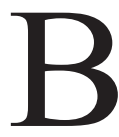

современном социогуманитарном знании ${ }^{1}$ интерес к проблемам, связанным с обеспечением безопасности на разных уровнях кол-

\footnotetext{
${ }^{1}$ Статья подготовлена в рамках выполнения государственного задания № 28.1475.2014/K Минобрнауки России «Гражданская и этническая идентичности в системе сохранения социальной безопасности населения приграничных территорий Российской Федерации».
}

лективной и индивидуальной жизнедеятельности человека, не ослабевает и более того - формирует определенный научный дискурс, актуализирующий данную проблематику в различных аспектах. С позиций сохранения государственности вопросы обеспечения безопасности, как известно, приобретают национальный характер и рассматриваются прежде всего как механизм сохранения суверенитета и самих основ государственного строя. В любом случае 
эти и другие стороны обеспечения безопасности принято напрямую связывать с правовыми особенностями и внешней и внутренней политикой страны. При этом соблюдение прав и свобод человека и гражданина должно оставаться не только конституционно закрепленной и гарантированной ценностью для государства, но и мерой ответственности государства перед обществом и личностью. Безопасность и политика становятся взаимосвязанными ценностно-смысловыми системами, но с упором на социальные механизмы достижения стабильности внутри страны. Присущие системе обеспечения безопасности на государственном уровне выраженные институциональные характеристики свидетельствуют о том, что «социетальные» интересы государства являются доминирующими, а «человекоцентричные» практически исключаются. Между тем система обеспечения национальной безопасности не может идти в разрез с философией государства, обязательным элементом которой является безопасность в самом широком смысле этого слова.

Философия государства и философия государственности не могут восприниматься или рассматриваться как некие абстрактные явления. Кроме того, именно эти категории, на наш взгляд, в наибольшей степени определяют не только правовой, социально-экономический и социально-политический вектор развития государства, но и участие в этих сложных и противоречивых процессах человека, не должностного лица, связанного обязанностями с органом власти, а именно человека как носителя культуры и обязательного участника во взаимодействии общества и государства. Когда речь заходит о безопасности никто не думает о философии государства, в лучшем случае признает ее вторичной или отвлеченной характеристикой повседневного бытия страны и ее народа. Однако философия государства представляет собой такую ценностносмысловую систему, которая, базируясь на исконных ценностях и нормах, традициях и обычаях, а также на культурных универсалиях, задает ключевые позиции для развития государства и сохранения его независимости, авторитетности в международном пространстве, безопасности и целостности. Таким образом, именно в философии государства появляется одна из важнейших особенностей развития государства - обеспечение безопасности. В отличие от философии государственности, соотносимой с культурно-историческим и социокуль- турным процессом становления и развития государства как такового, философия государства является своего рода программой жизни для каждого человека, для социальных групп и общества в целом. Такая программа позволяет разграничить опасность и безопасность, ценность и антиценность, норму и антинорму. В социально-гуманитарных науках, повидимому, должен сложиться такой подход, когда исследование любого из актуальных социальных вопросов необходимо «пропускать» через систему этих или других дихотомий, «схватывающих» саму природу социальных отношений и различные отклонения в них. Выяснение «границ» опасности и безопасности позволит дифференцировать не только социальные механизмы, направленные на преодоление опасности и, напротив, обеспечение безопасности, но и установить приоритеты ценностных исканий общества. В этом смысле такие искания скорее всего будут соотносимы с общечеловеческими ценностями, поскольку именно они - ценностные абсолюты цементируют социальные связи и отношения и не позволяют им расподобиться и утратить свою роль в развитии государства. Вместе с тем если внимание исследователя приковано к феномену безопасности, то в этом случае практически не берется в расчет явление опасности. Очевидно, что это продиктовано «технологическими» соображениями - опасность в большей степени предстает как философская категория, поэтому ее осмысление связано с установлением антропологии, психологии, культурологии опасности, безопасность - это прежде всего такое состояние мира и жизни, которое позволяет человеку, обществу и государству развиваться в настоящем и будущем. В этом смысле акцент на изучении именно феномена безопасности, а не опасности, вполне понятен и не вызывает сомнений. Исследователи обладают таким эмпирическим потенциалом и технологиями, которые позволяют измерить и представить показательные результаты о состоянии мира и жизни человека, общества и государства.

Немаловажное значение при рассмотрении проблем, связанных с обеспечением безопасности, имеет культуроцентричный ракурс. Как правило, если речь идет о безопасности, то исследователи делают упор на социоцентричный характер развития данного феномена. Между тем сегодня, когда мир находится в состоянии «ответа на вызовы», необходимо учитывать и первооснову многих со- 


\section{Политика и общество 8 (116) • 2014}

циальных явлений, проблем и испытаний; следовательно, важность приобретает обращение к ценностно-нормативной системе. Безопасность как феномен социального бытия касается всех структур повседневности, затрагивает интересы всех субъектов социальных отношений, и в то же время безопасность обеспечивается многими структурами, которые подчинены социальному порядку и находятся, как правило, в ведении государства. Между тем безопасность не может не являться элементом ценностно-нормативной системы общества. В этом смысле следует иметь в виду, что обеспечение безопасности прежде всего соотносится с нормативной системой (на институциональном уровне взаимодействия общества, человека и государства), в то время как для оценки эффективности мер по обеспечению должной безопасности важно рассматривать безопасность и в системе ценностных установок общества. В том случае, когда безопасность понимается именно в таком ключе - ценностно-нормативном, - не возникает особых сложностей и сводятся к минимуму неэффективные или малоэффективные способы обеспечения всесторонней безопасности. Иными словами все предлагаемые меры по обеспечению безопасности должны учитывать специфику ценностно-нормативного регулирования в том или ином обществе. Очевидно, что на разных исторических этапах развития обществ и государств, а также с учетом особенностей национального характера и ментальности способы и должные меры обеспечения безопасности будут существенным образом отличаться друг от друга. С другой стороны, безопасность в том смысле как она понимается достаточно широко и является по сути масштабным феноменом, не может быть исключена из перечня культурных универсалий. Именно этот смысл - безопасность как культурная универсалия - становится ключом к выработке эффективных мер по обеспечению безопасности в обществе и государстве.

Какие же обстоятельства и причины позволяют считать безопасность культурной универсалией, если со всей очевидностью устанавливаются социоцентричные приоритеты в понимании и представлениях о феномене безопасности? Всё чаще мы имеем в виду под безопасностью именно социальную безопасность. Этот термин стал общеупотребительным не только в практике деятельности различных государственных структур, но и в современном социогуманитарном знании. По-видимому, на том основании, что соииальность стала всеобъемлющей характеристикой человеческого индивидуального и коллективного бытия. Но при этом приходится решать сложную проблему о соотношении общества и личности. Социальность подтверждает доминанты общественных интересов и установок. Но в современных условиях, как нам кажется, необходимо вести речь о безопасности не просто как о социальном явлении, а как о социокультурном. И тогда логично использовать понятие социокультурной безопасности. Это важно еще и потому, что безопасность, как мы уже отметили, включается в ряд культурных универсалий. Основным признаком любой культурной универсалии считается преемственность культурных значений и кодов для практически всех культур и любой культуры независимо от места и времени их бытования и развития. Такие универсалии передаются из одного общества другому в порядке обмена социокультурным опытом между несколькими поколениями носителей культуры. Кроме того, они преломляют историю развития обществ и свидетельствуют о позитивных и катастрофических и кризисных этапах в существовании государств или обществ. В любой культурной универсалии существенны две стороны - ее материальное выражение и духовное содержание, но поскольку в пространстве культуры эти начала всё более носят условный характер и разделить их по четким основаниям не представляется возможным, то для типизации культурных универсалий следует использовать, по-видимому, социальный критерий. Любая культурная универсалия, таким образом, «схватывает» процесс взаимодействия общества, человека и культуры. Что касается безопасности как культурной универсалии, то она как никакая иная ценностно-смысловая система отражает не только процесс такого взаимодействия, но и его определенные результаты. По словам Р. И. Соколовой, «в условиях российской действительности остро стоит вопрос не просто о государстве (...), а о его единстве и жизнеспособности. Такое единство должно опираться на базовые, традиционные ценности и быть способным вдохновить людей, напомнить достойным и привлекательным содержанием, смыслом жизнь каждо- 
го человека, а также содействовать тому, чтобы народы России овладели результатами своего труда и творчества» ${ }^{2}$. Как видим, нередко в качестве своего рода «оператора» социальных связей и отношений выступают именно базовые, традиционные ценности, но, как известно, наряду с такими ценностями общества прирастают и другими - новыми и новейшими ценностными установками, некоторые из которых, возможно, балансируют между ценностями и антиценностями. Устанавливают истину в таких отношениях или же дифференцируют «новые» и «старые» ценности именно культурные универсалии.

Безопасность - это такая культурная универсалия, которая, с одной стороны, раскрывает эффективность взаимодействия общества, человека, культуры и государства (такое взаимодействие базируется на традиционных ценностях и нормах), с другой стороны, демонстрирует все возможные отклонения «к новым и новейшим» ценностям в результате такого взаимодействия. Как полагает М. О. Мнацаканян, «у каждого народа и общества свои, особые и характерные для них парадоксальные явления, процессы, ситуации...»³ Можно сказать, что культурные универсалии позволяют в сущности провести маркировку этих парадоксальных явлений и раскрыть тяготение культур и обществ к тем или иным традиционным мировоззренческим установкам и ценностям. В условиях кризиса культур и нахождения обществ в ситуации «вызова - ответа» заметно повышается роль культурных универсалий, апеллирующих к традициям и проверенным временем нормам коллективного и индивидуального человеческого бытия. Это важно еще и потому, что сама культура как ценностно-смысловая система подвержена дезинтегрирующим изменениям несмотря на, казалось бы, устойчивое стремление культур и носителей культур к позитивному взаимодействию, обмену социокультурным опытом. По мнению некоторых исследователей, культура сегодня представляет собой «арену интенсивных политических взаимодействий, противоречий и столкновений, при этом заметно трансформируется само понятие культуры, значение ее кодов, ком-

${ }^{2}$ Соколова Р. И. Сможет ли Россия выжить без идеологии? // Философские науки. 2014. № 1. С. 26.

${ }^{3}$ Мнацаканян М. О. Парадоксальный человек в парадоксальном обществе // Социол. исследования. 2006. № 6. С. 15. муникативных норм и практик, культурно-исторических нарративов» ${ }^{4}$. Очевидно, что подобные негативные процессы усложняют и меры, предпринимаемые государством для обеспечения национальной безопасности, и они не могут быть точечными, локальными, а значит, должны простираться во все сферы коллективной и индивидуальной жизнедеятельности человека. Самым, пожалуй, болезненным вопросом в этой связи становится вопрос о «сохранности» человека, когда смыслы социального доминируют в мире и составляют заботу государственных институтов. И, как справедливо полагает В. В. Налимов, «нужен новый ментальный потенциал (курсив автора цитаты. $-E$. П.)» . Таким потенциалом должен стать антропосоциетальный базис, который во взаимодействии человека и общества устанавливает в качестве фундаментального «ориентира» культуру.

Антропосоциетальный базис в обеспечении безопасности представляет собой систему социокультурных маркеров (универсалий), устанавливающих такое отношение человека и общества, которое не подвергается опасности со стороны кризисных проявлений мира, а также ценностно-нормативных трансформаций, имеющих негативные последствия. Часто используемое в современном научном дискурсе понятие человеческого капитала, по-видимому, можно было бы считать неотъемлемым элементом такого антропосоциетального базиса, однако, по слоам С. А. Кравченко, «содержание и характер человеческого капитала не имеют универсального характера: они изменяются во времени и пространстве, варьируются от страны к стране, специфичны в конкретных культурах, зависят от ментальности народа, его национального характера (курсив автора цитаты. - E. П.)» ${ }^{6}$. Как видим, человеческий потенциал может быть отнесен к культурным универсалиям с некоторыми оговорками, если иметь в виду особенности ментальности

\footnotetext{
${ }^{4}$ Следзевский И. В. Мультикультурализм: хрупкий баланс между интеграцией и дезинтеграцией // Общественные науки и современность. 2013. № 2. С. 125.

5 Налимов В. В. Критика исторической эпохи: неизбежность смены культуры в XXI веке // Вопросы философии. 1996. № 11. С. 73.

${ }^{6}$ Кравченко С. А. Становящаяся сложная социальная реальность: проблема новых уязвимостей // Социол. исследования. 2013. № 5. С. 8.
} 


\section{Политика и общество 8 (116) • 2014}

тех или иных групп носителей культуры. Вместе с тем из-за многогранности самой культуры и ее различных форм, в том числе и «менталитетосообразных», культурные универсалии не перестают быть «на страже» таких ценностей и норм, без которых эта ментальность утратила бы свою специфику и превратилась в некую гибридную массу.

Антропосоциетальный базис позволяет понять особенности социальной безопасности, обеспечительных мер, направленных на ее поддержание. Национальная безопасность «выводит» на первый план государство и его институты, этнобезопасность аккумулирует процессы внутри культуры, к примеру, продовольственная безопасность связана с различными проявлениями современного общества потребления и т.д. Характерной чертой социальной безопасности является ее антропосоциетальный базис, сформированный взаимными усилиями человека и общества, направленными на ценностно-нормативную стабилизацию. Как известно, само понятие социальной безопасности - довольно широкое, всеохватное. Оно может включать в себя и качество жизни, показателями которого, например, являются оценочный уровень жизни, качество социальной среды и экологической среды, социальное самочувствие ${ }^{7}$, и социальное благополучие ${ }^{8}$, а также затрагивать круг проблем, связанных с коррупцией и ее проявлениями, бюрократизмом и т.д. «Нагнетаемая атмосфера всеобщей продажности, - как отмечают некоторые исследователи, - возникающая во многом в силу простой экстраполяции бытового опыта граждан на все государственные институты, крайне негативно влияет на восприятие России как страны самими гражданами» ${ }^{9}$. Действительно, восприятие страны ее населением - это тоже немаловажный показатель социальной безопасности. Собственно, в этом и состоит роль антропосоциетального базиса: показать степень участия

\footnotetext{
${ }^{7}$ См.: Соколова Г. Н., Сечко Н. Н. Качество жизни населения Беларуси в контексте финансово-экономического кризиса // Социол. исследования. 2013. № 5.

${ }^{8}$ См.: Социальное благополучие населения современной Сибири: монография / под общ. ред. О. Н. Колесниковой. Барнаул, 2010.

${ }^{9}$ Толпегин П. В., Максимов Д. А. Общество и государство в России: пути развития в XXI веке // Право и политика. 2008. № 12. C. 2844.
}

и человека, и общества - и с различных сторон, и сообща - в обеспечении безопасности, но прежде всего на социокультурном уровне. Здесь важен и «бытовой опыт граждан», и повседневное поведение человека в обществе, и понимание сути идеи социальной справедливости (именно «идея социальной справедливости осуществляет интеграцию общества» - полагают авторы статьи о генезисе постиндустриального общества ${ }^{10}$ ). Безусловно, имеет значение и равновесие в ценностно-нормативной системе общества - «тотальная социальность», распространившаяся в современном мире с приоритетами общественными над личностными, все же заметно это равновесие нарушает. Более выделенными становятся ценности и нормы социального бытия и общественных интересов. Поэтому и социальная безопасность прежде всего обеспечивает сохранность таких установок. А между тем высшей ценностью в российском обществе признается человек, как постулирует Конституция России во второй статье. Разумеется, это не обозначает, что вся ценностнонормативная система должна демонстрировать «установки» исключительно в пользу личности, однако для эффективных и действенных мер, направленных на обеспечение социальной безопасности, необходимо в центр государственной заботы ставить именно человека, поскольку «человек объективен по отношению к другим людям, сообщество людей объективно по отношению к индивиду; история объективна по отношению к действительности и человеку, живущему в ней» ${ }^{11}$.

Социальная безопасность - явление социокультурного плана. Культурные универсалии, оказывающие влияние на обеспечение социальной безопасности, могут быть как традиционными, т.е. связанными с ценностями и нормами, на протяжении длительного времени актуальными для данного общества и культуры, так и могут быть новейшими или инновационными. К примеру, И. И. Кравченко называет высшей ценностью общее благо, а все ценности подразделяет на две группы

\footnotetext{
${ }^{10}$ Кочетков В. В., Кочеткова Л. Н. К вопросу о генезисе постиндустриального общества // Вопросы философии. 2010. № 2. C. 27.

${ }^{11}$ Кравченко И. И. Политические и другие социальные ценности // Вопросы философии. 2005. № 2. С. 3.
} 
- базисные и первичные ${ }^{12}$, однако ценности - это один из фундаментальных элементов ценностнонормативной системы, другим элементом является и антропосоциетальный базис, связующий воедино ценности и нормы. К первому типу культурных универсалий, составляющих такой базис, можно отнести следующие: 1) человек; 2) духовная жизнь человека и общества; 3) религия; 4) наука; 5) национальный характер; 6) образование; 7) язык; 8) природа; 9) здоровье и другие. Как видим, в этом перечне присутствуют ключевые для развития любого общества и государства культурные универсалии, и обеспечение социальной безопасности как раз заключается в сохранении данных приоритетов для конкретного общества и государства. При этом, разумеется, нужно иметь в виду, что культуры, принимая культурные универсалии и следуя им, допускают определенные аберрации или трансформации, опираясь исключительно на свой социокультурный опыт. Здесь речь можно вести и о национальной идее, и о социальной безопасности, а В. М. Межуев, к примеру, отмечает: «Подобно Европе, Россия искала и пыталась выразить в своей культуре некоторое универсальное начало (курсив наш. - Е. П.), способное объединять людей и народы в общепланетарном масштабе» ${ }^{13}$. Конечно, этот дух универсализма в наши дни «оброс» различными дискредитирующими обстоятельствами, если иметь в виду социально-политические санкции Европы и США против России. Коллапс ценностей и норм налицо, и тем более сложнее обеспечивать социальную безопасность в таких условиях.

Но социальная реальность динамична. Она диктует формирование и иных ценностно-смысловых и нормативных установлений. Поэтому культурные универсалии начинают складываться и на основе инновационных или новейших ценностей и норм. В числе таких культурных универсалий мы можем назвать следующие: 1) интернет и сети телекоммуникации; 2) экономоцентризм; 3) мультикультурализм; 4) социоцентризм и другие. Существование подобных универсалий сопряжено не только с остросоциальными проблемами, которые, как известно, всегда присутствовали на различных исторических этапах развития обществ, но

\footnotetext{
${ }^{12}$ Там же. С. 6.

${ }^{13}$ Межуев В. М. О национальной идее // Вопросы философии. 1997. № 12. С. 9.
}

и с социокультурными проблемами, вызванными прежде всего противоречиями в отношениях общества, государства, человека и культуры. Такие противоречия усложняют, и подчас довольно существенно, меры по обеспечению социальной безопасности. Но при этом проблема по-прежнему продолжает оставаться актуальной и практически неразрешимой в том смысле, что социальная безопасность - это результат усилий разных субъектов по стиранию негативных проявлений в отношениях общества и человека, человека и государства. Однако социальная безопасность еще не гарантирует хотя бы частичное, не говоря уже о полном, преодоление таких противоречий и конфликтов интересов, ценностей и норм. Утилитарные трактовки культуры и процессов, в ней происходящих, сами по себе не добавляют оптимизма исследователям, анализирующим социокультурные явления и феномены, более того - осложняют их позицию в обосновании тех или иных выводов. Так, например, тезис «культура - всё то, что не передается генетически, но приобретается с воспитанием» ${ }^{14}$ не может не вызывать критики; культурные геноти$n b l$ передаются от поколения к поколению, в противном случае любому носителю культуры пришлось бы всякий раз преодолевать сложный путь приобщения к ценностям и нормам своих предков. В равной степени это распространяется и на социальную безопасность - «чувство» социальной безопасности от одного поколения к другому передается посредством генотипов, формирующих у носителей культуры представления о самосохранности, порядке, справедливости и в конечном счете дифференцирующих добро и зло. Вопрос о добре и зле в этом ракурсе звучит не только как исключительно философский с апелляцией к мировоззрению и ценностно-смысловым абсолютам, но и как вполне социально заостренный, т.к. добро и зло есть две оси системы координат, в пространстве которой умещаются практически все ценности и нормы. Философский оттенок, пожалуй, имеет утверждение о том, что социальная безопасность - это своего рода граница между добром и злом, но с другой стороны, она эту границу нивелирует, поскольку меры, направленные на обеспе-

\footnotetext{
${ }^{14}$ Погребняк А. А., Расков Д. Е. Экономика как культура: возвращение к «спору о методах» // Обществ. науки и современность. 2013. № 2. С. 97.
} 


\section{Политика и общество 8 (116) • 2014}

чение социальной безопасности, не всегда добро и зло различают. По сути, социальная безопасность - это «общее дело», объединяющее людей вовсе не на основе политики или обыденных интересов, а в системе духовности. По этому поводу, например, исследователи пишут: «С духовным возрождением в стране пока не очень получается...по всей видимости, духовность, как и высшая власть, должна носить такой объединительный и надпартийный по своему содержанию характер, который окажется способным объединить людей вокруг практического осуществления Общего Дела» ${ }^{15}$.

Антропосоциетальный базис оказывает воздействие на формирование и развитие разных типов обществ, для которых вполне логично установление специфичных мер обеспечения социальной безопасности. Условно множественность типов и форм обществ в зависимости от роли личности, ее поведения, от характеристик государства и философии государственности, от состояния экономического и политического развития вполне соотносима и с особенностями социальной безопасности. Иными словами в конкретном типе общества скорее всего нужно применять различные меры по обеспечению социальной безопасности. Так, например, потребительское общество провоцирует принятие мер по безопасности потребления, прежде всего связанной с качеством питания, воды, бытовой техники, комфортностью жилья и т.д. Но общество потребления, кроме того, способствует и созданию определенного набора ценностей, главным образом, вещизма, а государство между тем вынуждено формировать для граждан т.н. продуктовую корзину, рассчитанную на месяц. Противоречия внутри общества потребления меняют ракурс «оценки» человека и самого общества: традиционные ценности и мировоззренческие установки как будто остаются «на бумаге» и подменяются другими ценностно-нормативными комплексами типа потребления, трендов, моды, масскульта и т.д.

Таким образом, когда речь заходит о социальной безопасности на институциональном уровне, обращают внимание на роль государственных и социальных институтов в обеспечении мер безопасности, но не меньшее значение имеет и ценностно-смысловой вектор анализа социальной безопасности, который позволяет учитывать онтологические основания в отношениях общества, человека, государства и культуры. Это обстоятельство в свою очередь позволит выявить более эффективные и действенные меры, направленные на обеспечение социальной безопасности.

\section{Библиография:}

1. Кочетков В. В., Кочеткова Л. Н. К вопросу о генезисе постиндустриального общества // Вопросы философии. 2010. №

2. Кравченко И. И. Политические и другие социальные ценности // Вопросы философии. 2005. № 2.

3. Кравченко С. А. Становящаяся сложная социальная реальность: проблема новых уязвимостей // Социол. исследования. 2013. № 5.

4. Межуев В. М. О национальной идее // Вопросы философии. 1997. № 12.

5. Мнацаканян М. О. Парадоксальный человек в парадоксальном обществе // Социол. исследования. 2006. №

6. Налимов В. В. Критика исторической эпохи: неизбежность смены культуры в XXI веке // Вопросы философии. 1996. № 11.

7. Погребняк А. А., Расков Д. Е. Экономика как культура: возвращение к «спору о методах» // Обществ. науки и современность. 2013. № 2 .

8. Следзевский И. В. Мультикультурализм: хрупкий баланс между интеграцией и дезинтеграцией // Общественные науки и современность. 2013. № 2.

9. Соколова Г. Н., Сечко Н. Н. Качество жизни населения Беларуси в контексте финансово-экономического кризиса // Социол. исследования. 2013. № 5.

10. Соколова Р. И. Сможет ли Россия выжить без идеологии? // Философские науки. 2014. № 1.

11. Социальное благополучие населения современной Сибири: монография / под общ. ред. О. Н. Колесниковой. Барнаул, 2010.

${ }^{15}$ Шевченко В. Н. О перспективах реформирования российского государства: современные дискуссии в науке и за ее пределами // Философские науки. 2013. № 7. С. 19. 
12. Толпегин П. В., Максимов Д. А. Общество и государство в России: пути развития в XXI веке // Право и политика. 2008. № 12 .

13. Шевченко В. Н. О перспективах реформирования российского государства: современные дискуссии в науке и за ее пределами // Философские науки. 2013. № 7.

14. Т.В. Владимирова Безопасность общества как устойчивость социального порядка в условиях возрастания девиации // Национальная безопасность / nota bene. - 2013. - 1. - C. 12 - 19. DOI: 10.7256/2073-8560.2013.01.2.

15. О. Н. Федорова Развитие правового регулирования информационной безопасности России // Политика и Общество. - 2012. - 4. - С. $64-67$.

16. В. П. Хрыков Информационное общество в России: условия и проблемы формирования // Политика и Общество. $-2011 .-6 .-$ C. $18-25$.

17. О. В. Остроухов Политический риск в аспекте национальной безопасности (основы оптимизации политического риска) // Национальная безопасность / nota bene. - 2012. - 2. - С. 30 - 38.

18. Андреев М.В. Конституционные и международные политико-правовые принципы обеспечения национальной безопасности // Право и политика. - 2013. - 6. - С. 803 - 808. DOI: 10.7256/1811-9018.2013.6.6446.

\section{References (transliteration):}

1. Kochetkov V. V., Kochetkova L. N. K voprosu o genezise postindustrial'nogo obshchestva // Voprosy filosofii. 2010. №

2. Kravchenko I. I. Politicheskie i drugie sotsial'nye tsennosti // Voprosy filosofii. 2005. № 2.

3. Kravchenko S. A. Stanovyashchayasya slozhnaya sotsial'naya real'nost': problema novykh uyazvimostei // Sotsiol. issledovaniya. 2013. № 5 .

4. Mezhuev V. M. O natsional'noi idee // Voprosy filosofii. 1997. № 12.

5. Mnatsakanyan M. O. Paradoksal'nyi chelovek v paradoksal'nom obshchestve // Sotsiol. issledovaniya. 2006. №

6. Nalimov V. V. Kritika istoricheskoi epokhi: neizbezhnost' smeny kul’tury v KhKhI veke // Voprosy filosofii. 1996.

7. Pogrebnyak A. A., Raskov D. E. Ekonomika kak kul'tura: vozvrashchenie k «sporu o metodakh»// Obshchestv. nauki i sovremennost'. 2013. № 2.

8. Sledzevskii I. V. Mul'tikul'turalizm: khrupkii balans mezhdu integratsiei i dezintegratsiei // Obshchestvennye nauki i sovremennost'. 2013. № 2.

9. Sokolova G. N., Sechko N. N. Kachestvo zhizni naseleniya Belarusi v kontekste finansovo-ekonomicheskogo krizisa // Sotsiol. issledovaniya. 2013. № 5.

10. Sokolova R. I. Smozhet li Rossiya vyzhit' bez ideologii? // Filosofskie nauki. 2014. № 1.

11. Tolpegin P. V., Maksimov D. A. Obshchestvo i gosudarstvo v Rossii: puti razvitiya v KhKhI veke // Pravo i politika. 2008. № 12 .

12. Shevchenko V. N. O perspektivakh reformirovaniya rossiiskogo gosudarstva: sovremennye diskussii v nauke i za ee predelami // Filosofskie nauki. 2013. № 7.

13. T.V. Vladimirova Bezopasnost' obshchestva kak ustoichivost' sotsial'nogo poryadka v usloviyakh vozrastaniya deviatsii // Natsional'naya bezopasnost' / nota bene. - 2013. - 1. - C. 12 - 19. DOI: 10.7256/2073-8560.2013.01.2.

14. O. N. Fedorova Razvitie pravovogo regulirovaniya informatsionnoi bezopasnosti Rossii // Politika i Obshchestvo. - 2012. - 4. - C. $64-67$.

15. V. P. Khrykov Informatsionnoe obshchestvo v Rossii: usloviya i problemy formirovaniya // Politika i Obshchestvo. - 2011. $-6 .-$ C. $18-25$.

16. O. V. Ostroukhov Politicheskii risk v aspekte natsional'noi bezopasnosti (osnovy optimizatsii politicheskogo riska) // Natsional'naya bezopasnost' / nota bene. - 2012. - 2. - C. $30-38$.

17. Andreev M.V. Konstitutsionnye i mezhdunarodnye politiko-pravovye printsipy obespecheniya natsional'noi bezopasnosti // Pravo i politika. - 2013. - 6. - C. 803 - 808. DOI: 10.7256/1811-9018.2013.6.6446. 